Hal : $5-8$

\title{
Pengaruh Waktu, dan Dosis Adsorben Terhadap Penghilangan Ion Fe dalam Air Sumur Menggunakan Zeolit Alam Teraktifasi secara Kolom Adsorbsi
}

\author{
DINI HARIYATI ADAM \\ Dosen Pendidikan Biologi STKIP Labuhan Batu \\ Email: dini_adam89@yahoo.com
}

Diterima Maret 2018 dan Disetujui Mei 2018

\begin{abstract}
ABSTRAK
Telah dilakukan penelitian tentang Pengaruh Waktu, dan Dosis Adsorben Terhadap Penghilangan Ion Fe dalam Air Sumur Menggunakan Zeolit Alam Teraktivasi.Penelitian ini memiliki tujuan untuk menghilangkan ion $\mathrm{Fe}$ yang terkandung dalam air sumur. Kolom yang digunakan menggunakan kolom kaca dengan ukuran panjang $15 \mathrm{~cm}$, diameter $1 \mathrm{~cm}$ secara batch dengan laju alir 1,5 mL/menit. Waktu adsorbsi dilakukan dengan variasi 15 menit; 30 menit; 45 menit dan 60 menit, sedangkan variasi adsorben yang digunakan yaitu : $0,5 \mathrm{~g} ; 1,0 \mathrm{~g}$; $1,5 \mathrm{~g} ; 2,0 \mathrm{~g}$. Dari hasil penelitian diperoleh semakin lama waktu ,bobot adsorben maka semakin meningkat pula kapasitas adsorbsi. Efisiensi penyerapan tertinggi berdasarkan waktu kontak adsorben yaitu pada menit 60 menit sebesar 99,04 \%., sedangkan efisiensi adsorbsi optimum berdasarkan bobot adsorben yaitu 2,0 gram dengan nilai efisiensi adsorbsi sebesar 98,01\%.
\end{abstract}

Kata Kunci :Adsorbsi, zeolit, ion Fe, efisiensi adsorbsi

\section{PENDAHULUAN}

Sumber air bersih sangat dibutuhkan makhluk hidup untuk melakukan berbagai kegiatan yang berasal dari air tanah, air permukaan dan air hujan. Adapun parameter kualitas air bersih berdasarkan Kep. Menkes RI 2002 yaitu kandungan ion besi $(\mathrm{Fe})$ tidak lebih dari 0,3 ppm agar tidak menimbulkanberbagai gangguan kesehatan.

Air sumur yang mengandung besi dapat menimbulkan rasa mual jika dikonsumsi. Besi dengan kadar lebih dari 1 ppm dapat merusak dinding usus dan menyebabkan terjadinya iritasi pada kulit dan mata sedanglan jika kadar lebih dari 10 ppm menimbulkan bau busuk. Tercemarnya air sumur oleh adanya kandungan ion $\mathrm{Fe}$ dapat ditandai dengan perubahan fisik seperti timbulnya warna, bau, rasa dan jika dikonsumsi akan terasa tidak enak.

Untuk mengurangi kontaminan dari kandungan logamFe dalam air bisadilakukan dengan berbagai cara salah satunyametode adsorpsi dengan menggunakan suatu bahanpenjerap yang disebut adsorben. Adsorbsi adalah proses akumulasi adsorbat pada permukaan adsorben yang disebabkan oleh gaya tarik antar molekul adsorbat dengan permukaan adsorben. Interaksi yang terjadi pada molekul adsorbat dengan permukaan kemungkinan diikuti lebih dari satu interaksi, tergantung pada struktur kimia masing-masing komponen.Adsorpsi dianggap sebagai metode yang ekonomis dan efektifuntuk menghilangkan kandungan logam karena biaya yang relatif murah, dapat diregenerasi (Pehlivan et al., 2013), dan relatif sederhana (Al-ayubi et al., 2010).

Proses adsorbsi terjadi pada permukaan pori-pori dalam adsorben, sehingga untuk bisa teradsorbsi, logam dalam cairan mengalami proses perpindahan massa logam dari cairan ke permukaan adsorben, difusi dari permukaan adsorben ke dalam adsorben melalui pori, perpindahan massa logam dari cairan dalam pori ke dinding pori adsorben dan adsorbsi logam pada dinding pori adsorben. Perpindahan massa logam dari cairan dalam pori ke dinding pori adsorben umumnya berlangsung sangat cepat, sehingga proses ini tidak mengontrol kecepatan adsorbsi secara keseluruhan.

Adsorben yangdigunakan dalam penelitian ini adalah zeolit alam. Adsorben 
zeolit alam keberadaannya melimpah di alam,memiliki kapasitas pertukaran ion yangtinggi, murah harganya, selektifitas yangtinggi dan bersifat stabil (Erdem dan Donat ; 2004). Menurut Abdur Rahman dan Budi Hartono bahwa air tanah yang dilewatkan pada kolom gelas berisi zeolit, kadar Fe dapat diturunkan sampai 55\%.

Suatu zat dapat digunakan sebagai adsorben bilamempunyai daya adsorpsi selektif, berpori atau mempunyai luas permukaan persatuan massa yang besar serta mempunyai daya ikat yang kuat terhadap zat yang hendak dipisahkan secara fisik maupun kimia. Luas permukaan spesifik zeolit berkisar yaitu 25,9 $\mathrm{m}^{2} /$ gram (setiawan dan Supriyana, 1999) dan ini berhubungan dengan struktur pori internal yang menyebabkan zeolit mempunyai sifat sebagai adsorben (Sembiring, 2003). Semakin luas permukaan pori-pori, semakin tinggi dayajerapnya, daya jerap arang aktif sangat besar.

Pengaktifan adsorben diharapkan dapat meningkatkan efisiensi adsorpsi. Untuk analisis kadar logam besi dilakukan menggunakan spektrofotometer serapan atom (SSA). Pemilihan metode spektrofotometer serapan atom karena mempunyai sensitifitas tinggi, mudah, murah, sederhana, cepat, dan cuplikan yang diperlukan sedikit serta tidak memerlukan pemisahan pendahuluan (Suyanta, et. al, 2015).Penelitian ini bertujuan untuk menentukan kondisi optimum zeolit alam dalam memisahkan ion Feberdasarkan pengaruh waktu dan bobot adsorben.

\section{METODOLOGI PENELITIAN}

Penelitian telah dilaksanakan pada bulan Februari sampai Maret 2018.Analisis logam Fe dilakukan di laboratorium USU.

Variabel bebas penelitian ini adalah waktu kontak adsorben dan bobot adsorben.Sedangkan variabel terikat adalah konsentrasi ion logam Fe.

Larutan standar Fe dibuat dengan cara melarutkan 0,1 gram $\left(\mathrm{NH}_{4}\right)_{2} \mathrm{Fe}\left(\mathrm{SO}_{4}\right) \cdot 6 \mathrm{H}_{2} \mathrm{O}$ dalam labu ukur $10 \mathrm{~mL}$. Sampel diencerkan menggunakan akuades danditepatkan hingga $1 \mathrm{~L}$ hingga tanda batas.Kemudian selanjutnya diencerkan dengan pengenceran bertingkat hingga diperoleh larutan stok $\mathrm{Fe}$ dengan konsentrasi $10 \mathrm{mg} / \mathrm{L}$.

\section{a. Preparasi Sampel Zeolit alam}

Zeolit dihaluskan dengan ukuran 200 mesh kemudian dicuci dengan akuadest dan dikeringkan pada suhu $100{ }^{\circ} \mathrm{C}$ dan disimpan dalam desikator.

\section{b. Proses Aktivasi Adsorben}

Aktivasi adsorben dilakukan dengan menggunakan $\mathrm{HCl}-\mathrm{NaOH}$.Sebanyak \pm 100 gram adsorben dicuci dengan akuadessambil diaduk menggunakan magnetic stirrer kecepatan 200 rpm selama 30menit, kemudian dicuci dengan larutan $\mathrm{HCl} 1 \mathrm{M}$ menggunakanmagnetic stirrer kecepatan $200 \mathrm{rpm}$ selama 30 menit.Adsorben disaring dan dicuci beberapa kali menggunakanakuades hingga $\mathrm{pH}$ mendekati 7.Adsorben direndam di dalamlarutan $\mathrm{NaOH} 1 \mathrm{M}$ selama 24 jam, dan disaring. Adsorben selanjutnya dicuci beberapa kali denganakuades hingga $\mathrm{pH}$ mendekati 7 dan disaring selanjutnya dikeringkan di dalam oven dengan suhu $60^{\circ} \mathrm{C}$ selama 24 jam hingga kering merata.

\section{c. Pengaruh Waktu Kontak Adsorbsi terhadap Adsorbsi lon Fe}

Sebanyak $100 \mathrm{~mL}$ larutan $\mathrm{Fe} 10 \mathrm{mg} / \mathrm{L}$ dimasukkan ke dalam 5 buah erlenmeyer masing-masing ditambahkan zeolit $1,0 \mathrm{~g}$ kemudian campuran dishaker dengan variasi waktu 15, 30, 45, 60 menit. setelah itu disaring dan filtratnya dianalisis menggunakan AAS.

\section{d. Pengaruh dosis adsorben Zeolit terhadap Adsorbsi Ion Fe}

Sebanyak $100 \mathrm{~mL}$ larutan ion Fe $10 \mathrm{mg} / \mathrm{L}$ dimasukkan ke dalam 5 buah erlenmeyer masing-masing ditambahkan zeolit0,5 g ; $1,0 \mathrm{~g} ; 1,5 \mathrm{~g} ; 2,0 \mathrm{~g}$. Kemudian dikocok denganshaker. Proses adsorpsi dilakukan selama 60 menit,setelah itu disaring. Filtratdianalisis menggunakan AAS.

\section{e. Kolom Adsorbsi}

Kolom adsorpsi disiapkan menggunakan kolom kaca bercerat yang berisi zeolit kondisi optimum dengan tinggi adsorben $5,5 \mathrm{~cm}$ dan diameter kolom $1 \mathrm{~cm}$. Sebelum digunakan, kolom tersebut dibilas menggunakan akuades, dan dimasukkan sedikit glass wool. Selanjutnya ditentukan laju alir kolom dengan akuades.

$$
\text { Sampel air sumur yang }
$$
mengandung logam besi dilewatkan ke 
Hal : $5-8$

kolom berisi zeolit yang teraktivasi. Filtrat ditampung setiap interval waktu 10 menit selama 1 jam dan dianalisis menggunakan spektrofotometer serapan atom (SSA). Kemudian ditentukan efisiensi penyerapan (Wardiyati et al., 2007).

\section{HASIL DAN PEMBAHASAN}

Proses aktivasi pada adsorben zeolit alam bertujuan untuk meningkatkan luas permukaan adsorben sehingga kapasitas adsorbsi dan kualitas juga meningkat (Mandasari \& Purnomo, 2016)Pencucian adsorben menggunakan $\mathrm{HCl}$ bertujuan untuk menghilangkan kandungan oksidaoksida logam yang terkandung di dalamnya. Kemudian adsorben direndam menggunakan larutan $\mathrm{NaOH}$ agar terbentuk senyawa silikat yang dapat meningkatkan luas permukaan zeolit.

\section{a. Pengaruh Waktu Kontak terhadap} Adsorbsi lon Fe

Waktu kontak merupakan salah satu faktor yang dapat mempengaruhi nilai efisiensi adsorbsi.Waktu kontak optimum adalah ketika adsorben yang digunakan untuk menyerap larutan $\mathrm{Fe}$ menghasilkan nilai efisiensi terbesar.

Proses adsorbsi dilakukan dengan cara memasukkan $100 \mathrm{~mL}$ larutan Fe dengan konsentrasi $10 \mathrm{mg} / \mathrm{L}$ dan penambahan adsorben sebanyak 1,0 g. Variasi waktu kontak yang digunakan yaitu 15, 30, 45, dan 60 menit.

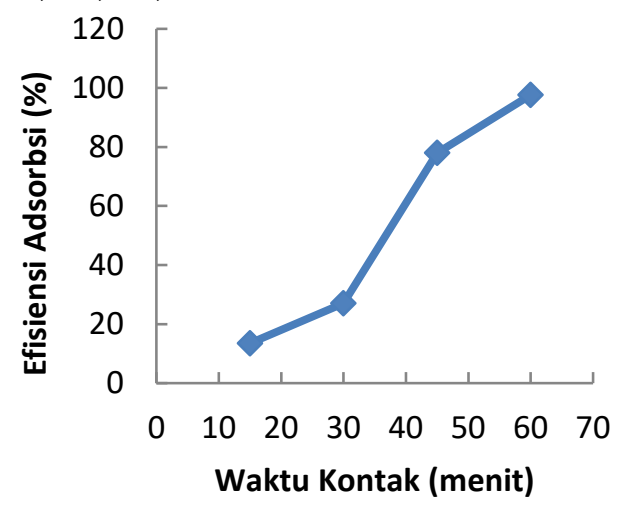

Gambar 1.Kurva hubungan antara waktu kontak terhadap efisiensi adsorbsi larutan $\mathrm{Fe}$

Dari hasil dapat dilihat bahwa terdapat hubungan linear antara waktu kontak dengan efisiensi adsorbsi.Semakin lama waktu kontak maka efisiensi adsorbsi juga semakin meningkat. Efisiensi adsorbsi larutan $\mathrm{Fe}$ terbesar yaitu pada saat waktu penyerapan selama 60 menit yaitu 99,04\%.

\section{b. Pengaruh Penambahan Zeolit terhadap Adsorbsi Ion Fe \\ Dari kurva dapat dilihat bahwa semakin besar penambahan bobot} adsorben maka nilai efisiensi adsorbsi juga meningkat yang ditandai dengan nilai efisiensi terbesar yaitu pada penambahan 2,0 gram zeolitsebesar 98,01\%. Hal ini disebabkan karena jumlah partikel, luas permukaan dan ruang kosong yang melimpah dari pori sehingga dapat menyerapan $\mathrm{Fe}$ secara maksimal, juga menyatakan bahwa pada saat penambahan bobot maka akan meningkatkan efisiensi adsorbsi.

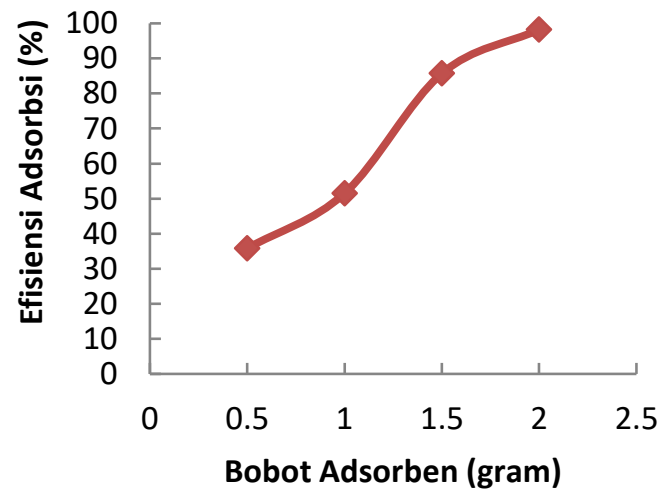

Gambar 2.Kurva hubungan antara penambahan bobot zeolit terhadap efisiensi adsorbsi

\section{c. Kolom Adsorbsi}

Setelah diperoleh kondisi optimum maka percobaan dilanjutkan menggunakan kolom adsorbsi dengan kolom kaca secara batch. Pengaturan laju alir influen (adsorbat) yang masuk ke dalam kolom adsorben dengan efluen (sisa adsorbat yang tidak terjerap) yang keluar dari kolom adsorben dilakukan dengan menggunakan akuades. Pengaturan laju alir dilakukan dengan cara membuka kolom sehingga akuades yang terdapat pada kolom akan menetes keluar, hal ini dilakukan hingga didapatkan laju alir yang konstan. Laju alir pada penelitian ini didapatkan sebesar 1,5 $\mathrm{mL} /$ menit.

Proses adsorpsi dilakukan menggunakan kolom kaca dengan ukuran panjang $15 \mathrm{~cm}$ dan diameter $1 \mathrm{~cm}$ dengan bobot adsorben sebanyak 2,0 g kemudian dialirkan sampel air sumur. Waktuadsorbsi dilakukan selama 60 menit, dengan interval 10 menit. Hasil penelitian menggunakan 
kolom adsorbsi dapat dilihat pada Gambar 3.

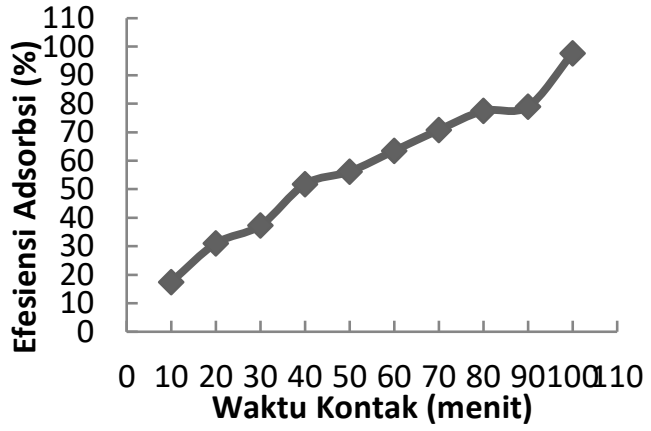

Gambar 3.Pemisahan ion $\mathrm{Fe}$ menggunakan kolom adsorbsi yang berisi adsorben.

Dari gambar 3 diketahui bahwa efisiensi adsorbsi terbesarpada saat waktu kontak 80 menit yaitu $97,7 \%$. Pada waktu kontak 90 dan 100 menit terjadi penurunan efisiensi adsorbsi disebabkan karena telah jenuhnya adsorben zeolit.

\section{DAFTAR PUSTAKA}

Abdur Rahman dan Budi Hartono.(2004). Penyaringan Air Tanah Dengan Zeolit Alami Untuk Menurunkan Kadar Besi dan Mangan.Jurnal Makara, Kesehatan. 8(1): 1-6.

Al-ayubi, M. C., H. Barroroh, D. Chandra. 2010. Studi Kesetimbangan Adsorbsi Merkuri(II) pada Biomassa Daun Enceng Gondok. Alchemy, 1(2), 55103.

Department Kesehatan RI., 2002, Keputusan Menteri Kesehatan RI, Nomor 907 Tahun 2002 Tentang Persyaratan Kualitas Air Minum.

Erdem, E., Karapinar, N., and Donat, R., 2004, The Removal Heavy MetalCations by Natural Zeolites, Journalof Colloid and Interface Science 280,309-314, Department of ChemistryEngineering, Faculty of Engineering, Pamukkale University, Denizli,Turkey.

Mandasari, I., \& Purnomo, A. (2016). Penurunan Ion Besi ( $\mathrm{Fe}$ ) dan Mangan ( $\mathrm{Mn}$ ) dalam Air dengan Serbuk Gergaji Kayu Kamper. Jurnal Teknik ITS, 5(1), 1-6.

Pehlivan, E., H. T. Tran, W. K. I. Ouédraogo, C. Schmidt, D. Zachmann, M. Bahadir. 2013.
Sugarcane Bagasse Treated with Hydrous Ferric Oxide as A Potential Adsorbent For The Removal Of As(V) From Aqueous Solutions. Food Chem., 138, 133-138.

Sembirin, $S$ dan Karo-Karo, $P$. 2007.Pengaruh Suhu Kalsinansi terhadap Karakterisasi Termal dan Mikrostruktur Silika Sekam Padi. J. Sains MIPA, Edisi Khusus 2017. Vol 13. Hal 233-239.

Setiawan, D dan Supriyatna D. 1999. Sintesis Zeolit

Suyanta, H.I, Kholid, Dan S. Bambang. 2015. Pemisahan lon Logam $\mathrm{Ca}$ dan Fe dalam Air Sumur Secara KolomAdsorpsi Dengan Zeolit Alam dan Karbon Aktif. Jurnal Sains Dasar. Vol.4(1), 87-91

Wardiyati, S., S. Budi dan Ridwan. 2007. Adsorpsi lon $\mathrm{Pb}^{2+}$ dan $\mathrm{Ni}^{2+}$ oleh Nanopartikela-

$\mathrm{Fe}_{2} \mathrm{O}_{3} / \mathrm{Fe}_{3} \mathrm{O}_{4}$. Akreditasi LIPI, 536, 83-87. 